Quality : Jurnal Kesehatan

Volume 15, Nomor2x Tahun 2021

pISSN : 1978-4325, eISSN : 2655-2434, DOI: 10.36082/qjk.v15i2.305

\title{
PENINGKATAN STATUS KESEHATAN LANSIA DENGAN HIPERTENSI MELALUI MODEL CONTINUITY OF CARE BERBASIS PEMBERDAYAAN KADER DAN LANSIA
}

Ni Made Riasmini ${ }^{1}$

${ }^{1}$ Politeknik Kesehatan Kemenkes Jakarta III, Indonesia

\begin{tabular}{ll}
\hline Info Artikel & Abstrak \\
\hline Genesis Naskah: & $\begin{array}{l}\text { Perawatan berkelanjutan (continuity of care) pada lansia merupakan salah satu strategi } \\
\text { kesehatan yang efektif agar kader lansia mampu membantu lansia dalam mengatasi masalahnya. }\end{array}$ \\
Submission:11-07-2021 & Perawatan berkelanjutan pada lansia dapat dilakukan melalui pelayanan di masyarakat dengan \\
Revised:26-11-2021 & keterlibatan kader lansia serta memberdayakan potensi lansia, yang nantinya diharapkan \\
Accepted:26-11-2021 & mampu meningkatkan status kesehatan lansia dengan hipertensi. Penelitian ini bertujuan untuk \\
& mengetahui pengaruh model continuity of care (CoC) berbasis pemberdayaan kader dan lansia \\
& terhadap status kesehatan lansia dengan hipertensi di Wilayah DKI Jakarta. Desain penelitian \\
Kata Kunci: & menggunakan quasi experiment with control group design dengan jumlah sampel sebesar 62 \\
(Perawatan Berkelanjutan, & lansia yang tinggal di wilayah DKI Jakarta. Analisis data menggunakan uji $t$-test, uji chi-square \\
Hipertensi, pemberdayaan, & dan Regresi Logistik Ganda. Hasil penelitian menunjukkan ada perbedaan bermakna status \\
status kesehatan, lansia & kesehatan lansia sebelum dan sesudah penerapan model pada kelompok intervensi (p \\
& value=0.001). Demikian juga ditemukan perbedaan bermakna status kesehatan lansia sesudah \\
& penerapan model antara kelompok intervensi dan kontrol (p value=0.001). Rekomendasi: agar \\
& intervensi model CoC berbasis pemberdayaan kader dan lansia dapat dijadikan sebagai salah \\
& satu intervensi pendampingan lansia yang bisa diterapkan di tatanan komunitas.
\end{tabular}

\section{IMPROVED HEALTH STATUS AMONG ELDERLY WITH HYPERTENSION THROUGH CONTINUITY OF CARE MODEL BASED ON THE EMPOWERMENT OF CADRES AND THE ELDERLY}

\footnotetext{
Keywords:

Continuity of Care,

Hypertension,

Empowerment of Cadres
}

and Elderly, Health Status 


\section{Pendahuluan}

Peningkatan jumlah lansia yang diikuti dengan peningkatan umur harapan hidup menjadi salah satu indikator keberhasilan pembangunan kesehatan sekaligus merupakan tantangan pembangunan. Peningkatan kualitas hidup lansia dapat dilakukan melalui pembangunan SDM kelanjutusiaan. Pemerintah beserta Kementerian menyiapkan rancangan Strategi Nasional (Stranas) kelanjutusiaan 2018-2025, untuk meningkatkan kualitas hidup lansia melalui pembangunan SDM kelanjutusiaan, penguatan intitusi pelaksana kelanjutusiaan, perlindungan sosial, jaminan pendapatan, peningkatan derajat kesehatan lansia, perlindungan pemenuhan hak lansia (BPS, 2017). Program lanjut usia diharapkan mampu mejadikan lansia lebih mandiri, bermartabat dan produktif.

Keberadaan lansia di Indonesia terus meningkat, sehingga diperlukan kebijakan yang sesuai dengan kebutuhan lansia dengan mempertimbangkan segala aspek kehidupan lansia. Lansia merupakan kelompok rentan (vulnerable) terhadap masalah kesehatan (Stanhope \& Lancaster, 2015). Berdasarkan hasil Susenas (2017), angka kesakitan lansia sebesar 26,72\% artinya dari 100 lansia terdapat sekitar 27 lansia yang sakit. Hampir separuh lansia mengalami keluhan kesehatan dalam sebulan terakhir, yang dipengaruhi oleh penyakit yang berkaitan dengan faktor umur. Kondisi kesehatan lansia, sering diikuti dengan masalah multiple desease seperti hipertensi, diabetes mellitus, rheumatik dan penyakit infeksi lainnya.

Hipertensi termasuk dalam sepuluh penyakit tertinggi. Menurut WHO penderita hipertensi terus meningkat secara global dan diprediksi pada tahun 2025 sekitar 29\% terjadi hipertensi pada orang dewasa di seluruh dunia. Prevalensi hipertensi di Indonesia berdasarkan hasil survey indikator kesehatan nasional 2016 meningkat menjadi $32,4 \%$. Peningkatan hipertensi diikuti dengan peningkatan penyakit yang menyertai seperti stroke, penyakit jantung, gagal ginjal. Penyakit hipertensi merupakan salah satu penyakit katastronik yang tidak hanya memiliki angka kematian tinggi tetapi membebani ekonomi keluarga dan meningkatn beban Negara yang harus ditanggung melalui jaminan kesehatan nasional $(\mathrm{JKN})$. Peningkatan jumlah penderita hipertensi disebabkan karena faktor risiko yang dikategorikan menjadi dua bagian yaitu faktor-faktor yang dapat dimodifikasi seperti aktivitas fisik, diet, asupan

(C) Poltekkes Kemenkes Jakarta I

J1. Wijaya Kusuma No. 47-48 Cilandak Jakarta Selatan, Indonesia email: jurnalquality@poltekkesjakarta1.ac.id natrium berlebih, merokok, obesitas, konsumsi alkohol berlebih, dan kelebihan berat badan. Serta faktor yang tidak dapat dimodifikasi seperti jenis kelamin, usia dan riwayat keluarga (Krothe \& Clendon, 2016). Hipertensi yang tidak terkontrol terutama pada lansia merupakan masalah kesehatan masyarakat yang terkait dalam hal morbiditas, mortalitas, dan beban ekonomi (Ogedegbe et al, 2013)

Peningkatan derajat kesehatan untuk mengatasi masalah kesehatan lansia dapat dilakukan melalui pemberdayaan keluarga dan kader lansia. Disamping itu, pemberdayaan lansia tidak kalah penting meliputi peningkatan kemampuan fisik, mental spiritual, sosial, pengetahuan dan ketrampilan agar lansia siap didayagunakan sesuai kemampuan masing masing, sehingga lansia dapat melakukan fungsi sosialnya dan berperan aktif dalam bermasyarakat. Pemberdayaan (empowerment), yaitu dorongan atau pemberian kekuatan kepada keluarga dan masyarakat berupa dukungan, kekuatan, ide baru dan kemandirian dalam membentuk pengetahuan baru (Stanhope \& Lancaster, 2016).

Sebagai upaya peningkatan kesejahteraan lansia, pemberdayaan diarahkan untuk mengembangkan daya (potensi) individu maupun kolektif penduduk lansia, sehingga mereka dapat meningkatkan kemampuannya dalam berbagai aktivitas, baik sosial, ekonomi, maupun politis. Pemberdayaan lansia melalui peningkatan kemampuan untuk tetap aktif dalam aktivitas produktif merupakan salah satu anstisipasi agar lansia dapat mengurangi ketergantungan terhadap orang lain. Salah satu bentuk pemberdayaan terhadap lansia adalah dengan memberikan pengetahuan, dan pendidikan sepanjang hayat. (Undang-Undang Nomor 11 Tahun 2009)

Salah satu program pelayanan lansia dengan hipertensi di rumah melalui perawatan berkelanjutan (continuity of care), dilakukan oleh tenaga kesehatan professional dengan melibatkan masyarakat khususnya kader lansia. Pemberdayaan kader lansia merupakan salah satu strategi keperawatan komunitas yang diperlukan oleh perawat komunitas dalam pelayanan keperawatan lansia di rumah. Pemberdayaan bertujuan untuk memandirikan lansia agar dapat menolong dirinya sendiri sesuai kebutuhannya, berdasarkan potensi yang dimilikinya. Pemberdayaan kader sebagai perpanjangan petugas kesehatan dan pemberdayaan keluarga serta lansia merupakan

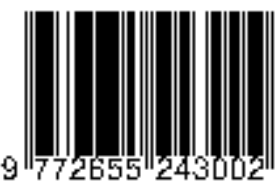


proses memilih, mengendalikan, dan membuat keputusan tentang kehidupan lansia, saling menghargai terhadap semua yang terlibat (Friedman, Bowden, \& Jones, 2010).

Perawatan berkelanjutan pada lansia dengan hipertensi merupakan salah satu strategi kesehatan yang efektif agar lansia mampu mengelola kesehatannya secara mandiri sesuai kemampuannya sehingga status kesehatannya meningkat. Perawatan berkelanjutan pada lansia dapat dilakukan melalui pelayanan di masyarakat dan keluarga, pelayanan pedesaan, daerah terpencil. Kontinuitas perawatan lansia merupakan faktor yang mempengaruhi kualitas pelayanan seperti pencegahan dan pengurangan cacat fisik, mental dan sosial lansia, meningkatkan kualitas perawatan pada lansia dengan kondisi penyakit kronis seperti hipertensi. Model continuity of care berbasis pemberdayaan kader dan lansia merupakan salah satu kegiatan pelayanan yang diberikan pada lansia di rumah untuk pengelolaan hipertensi, dimana lansia diberikan edukasi dan keterampilan untuk mampu melakukan deteksi dini serta pengambilan keputusan yang tepat jika memerlukan tindak lanjut perawatan, memerlukan keterlibatan petugas kesehatan di Puskesmas, kader lansia dan pemberdayaan potensi lansia. Tujuan penelitian adalah mengetahui pengaruh model continuity of care berbasis pemberdayaan kader dan lansia terhadap status kesehatan lansia dengan hipertensi di Wilayah DKI Jakarta.

\section{Metode}

Penelitian ini menggunakan desain quasi experiment pre-pos test with control group design. Penelitian ini dilakukan di Kecamatan Cipayung, Jakarta Timur, wilayah DKI Jakarta. Populasi adalah seluruh lansia di DKI Jakarta, sedangkan sampel penelitian adalah lansia dengan kriteria inklusi: 1) Berusia 60 tahun ke atas; 2) Masih mampu melakukan aktifitas atau tidak tirah baring; 3) Tidak mengalami ketunaan visual dan pendengaran; 4) Tidak mengalami kepikunan dan 5) Bersedia menjadi responden. Strategi sampling menggunakan cluster multistage method yaitu pemilihan sampel berdasarkan kluster dengan beberapa tahapan sesuai dengan wilayah geografis. Adapun tahapan dalam pengambilan sampel di 5 wilayah DKI Jakarta yaitu: 1) Memilih 1 Kotamadya di DKI Jakarta; 2) Memilih 1 kecamatan dari seluruh kecamatan di kotamadya terpilih; 3) Memilih 2 kelurahan dari seluruh

(C) Poltekkes Kemenkes Jakarta I

J1. Wijaya Kusuma No. 47-48 Cilandak Jakarta Selatan, Indonesia email: jurnalquality@poltekkesjakarta1.ac.id kelurahan yang ada di kecamatan tersebut, sebagai kelompok intervensi dan kelompok kontrol. Perhitungan besar sampel menggunakan uji hipotesis beda rata-rata pada dua kelompok independen dengan besar sampel sebanyak 62 orang (31 kelompok intervensi dan 31 kelompok kontrol). Instrumen yang digunakan untuk mengukur status kesehatan lansia adalah modifikasi dari Short Form Health Survey (SF-12) terdiri dari 12 item dengan menggunakan skala likert 1-5. Hasil uji validitas dengan skor dalam rentang 0.370-0.732 dan hasil uji reliabilitas dengan Cronbach's Alpha yaitu 0.863. Analisis data menggunakan analisis univariat, bivariat dan multivariat. Uji statistik menggunakan dependent t-test, independent t-test (data berdistribusi normal); uji chi-square dan uji Regresi Logistik Ganda. Seluruh responden telah mendapatkan penjelasan penelitian dan telah memberikan persetujuan untuk menjadi responden dengan menandatangani inform consent. Sebelum dilakukan penelitian, peneliti mendapatkan ijin melaksanakan penelitian dari Dinas Kesehatan Provinsi DKI Jakarta serta ethical clearance dari Komite Etik Poltekkes Kemenkes Jakarta III No. KEPK- PKKJ3/207/IV/2019.

Model Continuity of Care (Perawatan Berkelanjutan) melalui pemberdayaan kader dan lansia, ditujukan agar lansia mampu melakukan pencegahan dan perawatan hipertensi secara mandiri sesuai kebutuhan dan kemampuannya. Pengembangan Model ini diterapkan pada kelompok intervensi dengan kegiatan: 1)Pelatihan kepada perawat penanggung jawab program lansia puskesmas tentang pemberdayaan kader dan lansia dalam pengelolaan hipertensi (pelatihan dilakukan dalam 1 hari); 2) Pelatihan pada kader lansia tentang pendampingan kader terhadap lansia dalam pengelolaan hipertensi (1 hari); 3) Pendampingan lansia dilakukan oleh kader selama 8 minggu (2 kali seminggu); 4) Monitoring dan evaluasi dilakukan oleh perawat kepada kader lansia selama 8 minggu (1 kali seminggu). Untuk memenuhi etik penelitian terkait prinsip keadilan, pada kelompok kontrol walaupun tidak dilakukan intervensi khusus tetapi diberikan pelayanan standar.

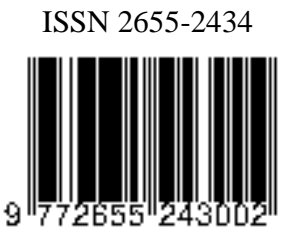




\section{Hasil}

\section{A. Karakteristik lansia}

Tabel 1. Skor karakteristik lansia berdasarkan usia, dan lama menderita hipertensi di Kec. Cipayung, Jakarta Timur wilayah DKI Jakarta $(n=62)$
B. Perbedaan Status Kesehatan Lansia sebelum dan sesudah intervensi Model CoC Berbasis Pemberdayaan Kader dan Lansia pada kelompok intervensi dan control

Tabel 3. Analisis Perbedaan Status Kesehatan Lansia

sebelum dan sesudah intervensi Model CoC Berbasis

DKI Jakarta

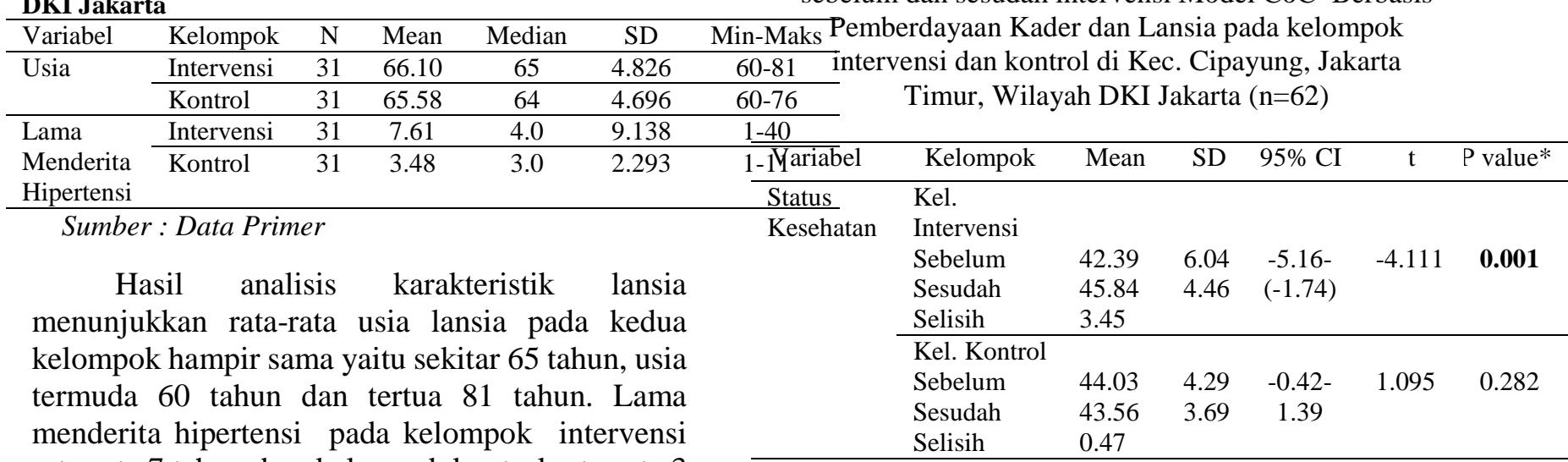
rata-rata 7 tahun dan kelompok kontrol rata-rata 3 tahun.

Hasil uji normalitas untuk variabel usia $(\mathrm{p}=0,328)$, lama menderita hipertensi $(0,064)$ dan status kesehatan lansia $(p=0,884)$. Hal ini menunjukkan bahwa ketiga variabel tersebut berdistribusi normal.

Tabel 2. Distribusi Karakteristik Lansia Berdasarkan Jenis Kelamin, Status Kawin dan Pendidikan di di Kec. Cipayung, Jakarta Timur wilayah DKI Jakarta $(n=62)$

\begin{tabular}{lcccccc}
\hline \multirow{2}{*}{ Variabel } & \multicolumn{2}{c}{ Kel.Intervensi } & \multicolumn{2}{c}{ Kel.Kontrol } & \multicolumn{2}{c}{ Total } \\
\cline { 2 - 7 } & $\mathrm{N}$ & $\%$ & $\mathrm{~N}$ & $\%$ & $\mathrm{~N}$ & $\%$ \\
\hline Jenis Kelamin & & & & & & \\
1. Laki-laki & 8 & 25.8 & 7 & 22.6 & 15 & 24.2 \\
2. Perempuan & 23 & 74.2 & 24 & 77.4 & 47 & 75.8 \\
\hline Status Kawin & & & & & & \\
1. Kawin & 22 & 71.0 & 18 & 58.1 & 40 & 64.5 \\
2. Janda/Duda & - & - & - & - & - & - \\
3. Tidak kawin & 9 & 29.0 & 13 & 41.9 & 22 & 35.5 \\
\hline Pendidikan & & & & & & \\
1. < SMU & 24 & 77.4 & 22 & 71.0 & 46 & 74.2 \\
2. $\geq$ SMU & 7 & 22.6 & 9 & 29.0 & 16 & 25.8 \\
\hline
\end{tabular}

Sumber : Data Primer

Hasil analisis karakteristik lansia menunjukkan bahwa mayoritas berjenis kelamin perempuan pada kedua kelompok; status kawin mayoritas menikah pada kedua kelompok, dan tingkat Pendidikan mayoritas dibawah SMU pada kedua kelompok.

\section{*dependent t test}

Hasil analisis menunjukkan terdapat perbedaan bermakna status kesehatan lansia pada kelompok intervensi sebelum dan sesudah intervensi Model CoC Berbasis Pemberdayaan Kader dan Lansia (nilai p= 0,001), Sedangkan pada kelompok kontrol tidak ada perbedaan bermakna status kesehatan lansia (nilai $\mathrm{p}=0,282$ ).

\section{Perbedaan Status Kesehatan Lansia Sesudah Intervensi Model CoC Berbasis Pemberdayaan Kader dan Lansia antara Kelompok Intervensi dan Kontrol}

Tabel 4. Analisis Perbedaan Status Kesehatan Lansia Sesudah Intervensi Model CoC Berbasis Pemberdayaan

Kader dan Lansia antara Kelompok Intervensi dan Kontrol di Kec. Cipayung, Jakarta Timur Wilayah DKI Jakarta $(n=62)$

\begin{tabular}{|c|c|c|c|c|c|c|c|}
\hline Variabel & Kelompok & $\mathrm{N}$ & Mean & SD & $\begin{array}{c}95 \% \\
\text { CI }\end{array}$ & $\mathrm{t}$ & $\begin{array}{c}\mathrm{P} \\
\text { value* }\end{array}$ \\
\hline $\begin{array}{l}\text { Status } \\
\text { Kesehatan }\end{array}$ & Intervensi & 31 & 45.84 & 4.49 & $\begin{array}{l}1.71- \\
6.26\end{array}$ & 3.54 & 0.001 \\
\hline Lansia & Kontrol & 31 & 41.84 & 4.44 & & & \\
\hline
\end{tabular}

*Independent $t$ test

Hasil analisis menunjukkan bahwa terdapat perbedaan bermakna status kesehatan lansia antara kelompok intervensi dan kelompok kontrol setelah dilakukan intervensi model Model $\mathrm{CoC}$ Berbasis Pemberdayaan Kader dan Lansia, dengan nilai $\mathrm{p}=0.001$. 
Pemilihan kandidat variabel multivariat dilakukan dengan menghubungkan semua variabel independen dengan variabel dependen menggunakan uji chi-square. Variabel independen yang menjadi kandidat untuk dimasukkan ke dalam model multivariat adalah yang memenuhi syarat $p$ value kurang dari 0.250 , sedangkan dari 5 variabel yaitu usia, jenis kelamin, status kawin, pendidikan dan lama menderita hipertensi tidak ada yang memenuhi syarat sehingga tidak dilanjutkan untuk uji multivariat. Dapat disimpulkan bahwa tidak ditemukan pengaruh karakteristik lansia terhadap status kesehatannya. Hal ini menunjukkan bahwa perubahan status kesehatan lansia murni karena pengaruh model $\mathrm{CoC}$ berbasis pemberdayaan kader dan lansia.

\section{Pembahasan}

Hasil penelitian menunjukkan bahwa penerapan model $\mathrm{CoC}$ berbasis pemberdayaan kader dan lansia dapat meningkatkan status Kesehatan lansia. Nilai rerata status kesehatan lansia pada kelompok intervensi sebelum penerapan model terlihat lebih tinggi dibandingkan rerata nilai status kesehatan lansia kelompok kontrol. Pada pengukuran setelah dilakukan penerapan model selama 8 (delapan) minggu ditemukan rerata nilai status kesehatan lansia kelompok intervensi mengalami kenaikan, sedangkan status kesehatan lansia kelompok kontrol mengalami sedikit penurunan. Kenaikan nilai status kesehatan lansia pada kelompok intervensi sebesar 2.74 poin, penurunan nilai status kesehatan lansia kelompok kontrol sebesar 0,77. Perbedaan nilai status kesehatan lansia kelompok intervensi dan kelompok kontrol sebagai pengaruh intervensi model melalui pendampingan yang dilakukan kader pada lansia dalam pengelolaan hipertensi di rumah. Hasil uji statistik menunjukkan ada perbedaan bermakna status kesehatan lansia sebelum dan sesudah penerapan model dengan nilai $\mathrm{p}<0,05$. Hal ini didukung oleh hasil penelitian Sahar (2017) ditemukan ada peningkatan skor status Kesehatan lansia setelah implementasi self help group. Peningkatan rerata status kesehatan lansia sesudah penerapan model sebagai akibat dari peningkatan kemampuan lansia dalam mengelola hipertensi. Kenaikan sedikit rerata status kesehatan lansia disebabkan karena evaluasi dilakukan hanya setelah 2 (dua) bulan penerapan model. Secara teori perubahan akan

(C) Poltekkes Kemenkes Jakarta I

J1. Wijaya Kusuma No. 47-48 Cilandak Jakarta Selatan, Indonesia email: jurnalquality@poltekkesjakarta1.ac.id terjadi minimal setelah dilakukan intervensi 3 (tiga) bulan. Pernyataan ini didukung oleh penelitian Croker dan Russel (2012), perubahan yang signifikan diperlukan waktu 6 (enam) bulan setelah diberikan intervensi yaitu berupa perubahan perilaku makan dan perubahan gaya hidup. Hal ini menggambarkan bahwa lamanya waktu pemberian intervensi model berpengaruh terhadap perubahan status kesehatan lansia.

Keberadaan kader sebagai social support lansia sangat diperlukan dalam pendampingan lansia hipertensi. Pelatihan kader dapat meningkatkan kemampuannya dalam melakukan pendampingan pada lansia dimana secara tidak lanngsung dapat mempengaruhi peningkatan status kesehatan lansia. Ada keterkaitan antara peran kader dalam pengelolaan hipertensi lansia di rumah dengan status kesehatan lansia. Perlunya dukungan sejalan dengan hasil penelitian Umayana (2015), yang mengatakan bahwa dukungan tokoh masyarakat dan kader sangat diperlukan pada kegiatan UKBM Posbindu, untuk meningkatkan informasi pada masyarakat. Kader lansia diharapkan dapat menjembatani antara petugas kesehatan dan lansia hipertensi. Hasil ini sejalan dengan penelitian yang menyatakan perlunya peran kader untuk kegiatan pendampingan kepada lansia dalam pengelolaan lansia hipertensi dimana lansia juga diajarkan untuk melakukan deteksi dini jika ada gejala dan pemanfaatan posyandu atau puskesmas dalam memantau kesehatannya. Beberapa penelitian menunjukkan bahwa ada hubungan yang bermakna antara peran kader dengan pemanfaatan Posbindu (Handayani, 2012: Aryani, 2011). Penelitian ini diperkuat oleh penelitian Anggraini (2015), kader mempunyai peran yang sangat dominan terhadap keberhasilan kegiatan Posyandu. Model perawatan berkelanjutan ini juga melibatkan peran kader dalam mendeteksi lansia, dimana kader dapat menghubungi perawat puskesmas dalam memfasilitasi lansia untuk mengakses pelayanan kesehatan. Hal ini sesuai dengan Peraturan Menteri Kesehatan RI, (2016), bahwa ketika cara pengobatan mandiri belum berhasil menghilangkan keluhan kesehatan, maka lansia akan mengunjungi fasilitas pelayanan kesehatan untuk berobat. Perencanaan pelayanan kesehatan harus dirancang berdasarkan kondisi lansia dan pola pelayanan yang dibutuhkan, mengacu pada pilihan sarana pelayanan kesehatan yang dapat diakses lansia dalam mencari pengobatan.

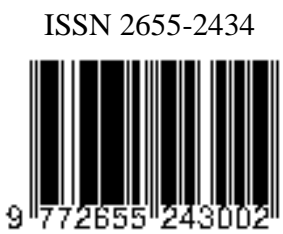


Hasil penelitian tidak ditemukan pengaruh karakteristik lansia sebagai variable confounding terhadap status kesehatan lansia, dimana perubahan status kesehatan murni karena pengaruh model. Hal ini kemungkinan karena adanya pendampingan yang dilakukan lansia secara rutin 2 (dua) kali seminggu dan adanya pemantauan secara rutin dari perawat puskesmas melalui kunjungan rumah yang dilakukan, sehingga status Kesehatan lansia terkontrol. Disamping itu, pengetahuan dan keterampilan yang diajarkan kepada lansia tentang deteksi dini hipertensi, penanganan masalah psikososial serta pemanfaatan pelayanan kesehatan yang dapat dilakukan jika timbul gejala, sangat bermanfaat bagi lansia dalam pengambilan keputusan dan lansia merasa diberdayakan. Semakin bertambah umur, lansia akan mudah berdaptasi terhadap kondisi dan perawatan yang diberikan. Hal ini didukung oleh Nygårdh et al, (2011) yang mengatakan bahwa responden yang makin dewasa akan mudah beradaptasi dalam praktik. Semakin cukup umur, maka tingkat kematangan dan kekuatan seseorang akan lebih baik dalam berpikir dan bertindak (Wawan \& Dewi, 2010). Kondisi ini diperkuat oleh Notoatmodjo (2012) yang mengatakan bahwa daya tangkap dan pola pikir seseorang terhadap suatu objek akan meningkat seiring dengan bertambahnya usia sehingga pengetahuan yang diperolehnya semakin membaik. Informasi yang disampaikan kader kepada lansia melalui pendampingan yang dilakukan 2 kali seminggu selama 8 minggu dapat meningkatkan pengetahuan dan keterampilan lansia sehingga status kesehatannya meningkat.

\section{Kesimpulan dan Saran}

Model Continuity of Care berbasis pemberdayaan kader lansia telah teruji efektif dalam meningkatkan status kesehatan lansia. Oleh karena itu, diharapkan model ini dapat dijadikan sebagai salah satu upaya pelayanan Kesehatan di masyarakat melalui pemberdayaan kader dan juga pemberdayaan potensi lansia agar mampu mengelola kesehatannya secara mandiri. Model ini juga dapat digunakan sebagai panduan bagi perawat komunitas dalam mengembangkan berbagai intervensi keperawatan yang melibatkan masyarakat dan juga keluarga sebagai pendukung utama bagi lansia.

\section{Daftar Pustaka}

Anggraini, (2015). Faktor Dominan mengikuti Kegiatan Posyandu di Dusun Ngentak. Journal Ners and Midwifery Indonesia. ISSN 2354-7642

Aryani, T. (2011). Identifikasi Faktor Perilaku dalam Pemanfaatan Posyandu di Puskesmas Bambanglipuro Kabupaten Bantul DI Jogjakarta. Depok.

Badan Pusat Statistik (2018). Survei Sosial Ekonomi Nasional (Susenas) 2017. Jakarta: BPS.

Badan Pusat Statistik (2017). Prosentase jumlah lansia di Indonesia. Jakarta

Croker,H \& Russel, M (2012). Family based behavioral treatment of chilhood obesity in a UK National Health Service setting : randomised controlled trial. International Journal of obesity.

Friedman, Bowden, Jones. (2010). Family Nursing Research, Theory \& Practice, $5^{\text {th }}$ ed. New Jersey : Pearson Educational Inc,

Handayani. (2012). Pemanfaatan Posbindu PTM di kecamatan Ciomas. Jakarta

Imaniyah, N. (2016). Gambaran Karakteristik Demografi dan Tingkat Kognitif Lansia di Balai Pelayanan Sosial Bisma Upakara Pemalang, Pekalongan.

Indrayani \& Ronoatmodjo, S. (2018). Faktorfaktor yang Berhubungan dengan Kualitas Hidup Lansia di Desa Cipasung Kabupaten Kuningan. Jurnal Kesehatan Reproduksi, 9(1), 2018: $\quad 69-78$ DOI: 10.22435/kespro.v9i1.892.69-78

Krothe, J. \& Clendon, J.( 2016). Perceptions of effectiveness of nurse managed clinics: A cross cultural study. Public Health Nursing, 23(3), 242-9.

Kementrian Kesehatan Republik Indonesia. (2013). Hasil Riset Kesehatan Dasar (Riskesdas) Tahun 2013. Jakarta:Kemenkes.

Peraturan Menteri Kesehatan No. 25 tentang Rencana Aksi Nasional Kesehatan Lanjut Usia Tahun 2016-2019

Ngadiran, A. (2019). Hubungan Karakteristik (Umur, Pendidikan, Lama Tinggal) dengan Tingkat Kecemasan Lansia di Panti Wreda Charitas Cimahi. Jurnal Ilmu Kesehatan. Vol.13, No.2, Desember 2019.

Notoatmodjo, S. ( 2012). Promosi kesehatan dan Perilaku Kesehatan. Jakarta: Rineka cipta. 
Novriyanti, I.D., Usnizar, F., \& Irwan. (2012). Pengaruh Lama Hipertensi Terhadap Penyakit Jantung Koroner Di Poliklinik Kardiologi RSUP. Dr. Mohammad Hoesin Palembang. Jurnal Kedokteran dan Kesehatan, Vol.1,No.1: 55-60.

Nygårdh et al (2011). Empowerment in outpatient care for patients with chronic kidney disease - from the family member's perspective. BMC Nursing, 10, p. 21.

Ogedegbe G, et al (2013). The Counseling Older Adults to Control Hypertension (COACH) trial: Design and methodology of a groupbased lifestyle intervention for hypertensive minority older adults. Contemporary Clinical Trial

Republik Indonesia. Undang-Undang Nomor 11 Tahun 2009 Tentang Kesejahteraan Sosial.

Sahar, J. et.al. (2017). Improved Health Status and Life Satisfaction among Older People following Self-Help Group Intervention in Jakarta. Current Gerontology and Gertiatric Research. Volume $2017 \quad$ Article ID 3879067 | https://doi.org/10.1155/2017/ 3879067

Stanhope, M \& Lancaster, J. (2016). Public Health Nursing Population Centered Health Care in The Community. $8^{\text {th }} \mathrm{Ed}$. St. Louise : Mosby

Umayana. (2015). Dukungan Keluarga dan Tokoh Masyarakat terhadap Keaktifan ke Posbindu PTM. Jurnal Kesehatan Masyarakat. ISSN 1858-1196.

Undang-Undang Republik Indonesia Nomor 11 Tahun 2009 tentang Kesejahteraan Sosial

Wawan \& Dewi. 2010. Teori \& Pengukuran Pengetahuan, Sikap, dan Perilaku Manusia. Yogyakarta : Nuha Medika 